\title{
Knowledge of Contraceptives and Unmet Needs of Family Planning among Adolescents Aged 15-19 Years
}

\author{
Article by Bernard Temitayo Ayobami \\ Master of Public Health, Texila American University, Nigeria \\ E-mail: ayobamyjomjom@gmail.com
}

\begin{abstract}
Background: It is essential to cater to unmet needs of contraception among the adolescent group if meaningful strides are to be achieved in the uptake of contraception and prevention of unwanted pregnancies in the society.

Objective: The main objective of the study is to assess the extent of knowledge and unmet needs of family planning among adolescents aged 15-20 years.

Methodology: Secondary data from the 2013 NDHS will be used. The sample was selected using a stratified three-stage cluster design consisting of 904 clusters, 372 in urban areas and 532 in rural areas.

A representative sample of 40,680 households was selected for the survey, with a minimum target of 943 completed interviews per state. A complete listing of households and a mapping exercise were carried out for each cluster over two months. The resulting lists of households serving as the sampling frame for the selection of regular households. A fixed sample take of 45 households were selected per cluster.

Data analysis: Analyses of quantitative data will be done in SPSS version 20. Chi-square test will be used to measure the strength of associations between the various variables where a $p$ value of $=$ or $<0.05$ will be considered statistically significant.
\end{abstract}

\section{Introduction}

\section{Background information}

There has been a growing interest in patterns of contraceptive use among adolescents, due, in particular, to the social, health, and economic relevance attached to pregnancy in this age group. Thus, there is a need for reproductive health education in school and college as well as robust research to determine the contraceptive needs of adolescents. It is however unfortunate that unwanted pregnancies and unsafe terminations of pregnancy still occur in large numbers. The World Health Organization (WHO) estimates that there are approximately 20 million of unsafe abortions every year, and estimates of maternal death as a result of abortion ranged between 60,000 to 100,000 per year. Therefore, family planning programs are very important and should be readily accessible to the community. One in ten pregnancies ends in an unsafe abortion, with Asia, Africa and Latin America accounting for the highest numbers. Each year, 19 million abortions are carried out under unsanitary or medically unfit conditions resulting in some 68,000 deaths. There is a marked increase in sexual activity in the adolescent population. Adolescents need access to information about sexual and reproductive health and contraceptive choices. They must be able to make their choice to prevent unwanted pregnancies based on informed knowledge of the health concerns and side effects of such contraceptives. Very often adolescents have wrong perceptions of reproductive health matters and consider that there is little risk of pregnancy following sexual activity, and exhibit at the same time an apparent ambivalence towards contraceptive practices that result in unplanned pregnancy While most people today look forward to the increase in human freedom provided by contraception, many have mixed feelings about the other side of the coin: There may be more sexual intercourse between unmarried couples, including the very young. For this reason, official sex education classes in schools, churches, and youth organizations often shy away from the subject. Furthermore, while most educators have little difficulty explaining the 
facts of human reproduction, they are usually ill at ease describing the various contraceptive methods because they then have to discuss the details of sexual activity ${ }^{1}$.(Australia's Med J. 2011; 4(1): 43-48. Published online 2011 Jan 31. doi: 10.4066/AMJ.2011.499)

Despite high knowledge about contraceptives among adolescents its use is low. Parental attitude towards adolescent contraceptive can adversely affect contraceptive use by adolescents. Both parents and adolescents had misconceptions about contraceptive use among adolescents. For the adolescents, being sexually active, and for the parents, belief that contraceptive use has advantages for adolescent users and their own prior contraceptive use were significantly associated with agreeing that sexually active adolescents should use contraceptives. Both parents and adolescents have high knowledge about modern contraceptive use in preventing both sexually transmitted infections and pregnancy. However, misconceptions and fear of side effects is preventing parents from discussing contraception with adolescents. Parents do not have the will to also encourage adolescents to use contraceptives. There is the need to educate both parents and adolescents to dispel the misconceptions about contraceptives. Contraceptive use among adults should be encouraged as adults on contraceptives are more likely to encourage adolescent contraceptive use. (Attitude of Parents and Adolescents Towards Contraceptive Use by Adolescents in Alajo, Ayawaso Central Submetro of Accra Maya, E.T. http://hdl.handle.net/123456789/5150-)

Taking a closer look at use of contraceptives in the adolescent age group is essential for reducing the burden of unmet needs of family planning and reducing maternal and infant mortality.

\section{Problem statement}

The high rates of adolescent fertility have been a particular concern in many countries. Reducing these levels in developing countries is one of the UN's Millennium Development Goals. But even in some developed countries, high rates persist, particularly in the United States, where the teen birth rate is much higher than the rate in the majority of developed countries. The adolescent fertility rate is defined as the number of births per 1,000 women ages 15 to 19. Having children this early in life exposes adolescent women to unnecessary risks. Their chance of dying is twice as high as that of a woman who waited until her 20s to begin childbearing. In addition, early childbearing greatly reduces the likelihood of a girl advancing her education and limits her opportunities for training and employment. Globally, the trend has certainly been downward, but there are very sharp differences in levels and trends across regions. (www.prb.org/Publications/Articles/2013/adolescent-fertility.aspx)

About 16 million women 15-19 years old give birth each year, about $11 \%$ of all births worldwide. Ninety-five per cent of these births occur in low- and middle-income countries. The average adolescent birth rate in middle income countries is more than twice as high as that in high-income countries, with the rate in low-income countries being five times as high. The proportion of births that take place during adolescence is about $2 \%$ in China, $18 \%$ in Latin America and the Caribbean and more than $50 \%$ in sub-Saharan Africa. (http://www.who.int/maternal_child_adolescent/topics/maternal/adolescent_pregnancy/en/)

It should not be surprising that adolescents in sub-Saharan Africa, who have the highest rates of fertility for their age in the world, face probably the highest risks of pregnancy-related mortality, of delivery complications, and of premature births or low-birth weight babies. Teenage pregnancy in Africa also has important social and economic outcomes, the most highly publicized of which stem from lost educational opportunities when pregnancy forces young women to leave school. ${ }^{1}$ Ideally, an investigation of the consequences of adolescent childbearing and sexuality should cover a wide range of outcomes that affect not only the young mother and her child, but also other family members and society at large. it has important effects on population levels and growth, especially in populations that appear to be governed largely by natural fertility. However, there is little direct evidence on the relationship between age at first marriage and completed family size in sub-Saharan Africa. 
Most reproductive health problems experienced by adolescents are also experienced by older women. But they are exacerbated among the young, whether by physical immaturity, primiparity, or social condemnation. In societies in which marriage and childbearing are expected to begin early, the majority of pregnancies produce highly valued children. Problems, when they do arise, arise primarily from the mother's physiological immaturity: Babies suffer from low birth weights and birth traumas, and young women are not mature enough to safely carry a fetus to term or to bear a baby. These problems are often compounded by the lack of adequate medical care. Although this pattern of early marriage and childbearing has received considerably less attention than has the emerging problem of pregnancy among urban schoolgirls, the number of women potentially at risk for these problems argues convincingly for including this pattern in any discussion of the consequences of adolescent fertility. Unmarried urban schoolgirls who become pregnant attract so much attention as it tends to be identified as the major locus of troublesome adolescent fertility in Africa. Inasmuch as urban schoolgirls are very young and physically immature they face risks of childbearing similar to those of women who get married early. However, because their risks extend through their education or training, urban girls are probably slightly older, on average, than their counterparts in the early-marriage group. Yet in the case of urban schoolgirls, social condemnation makes them reluctant to seek health services; hence, they suffer additional risks from lack of prenatal care and from unsafe abortions. They may also suffer an increase in risk of sexually transmitted diseases, although the evidence on this point is thin.

(Social Dynamics of Adolescent Fertility in Sub-Saharan Africa (1993)www.nap.edu/catalog/2220/social-dynamics-of-adolescent-fertility-in-sub-saharan-africa)

Teenage pregnancy of which adolescent pregnancy is a subset, affects both developed and developing countries, it is a universal problem. It is a major public health issue irrespective of the marital status of the adolescent. Teenage fertility, establishes the pace and level of fertility over a woman's entire reproductive life span (Panday, et al., 2009, UNICEF, 2005). Bulk of adolescent pregnancy in sub- Saharan Africa occurs within marriage. (World Health Organization, 2008) These adolescents tend to have more children than those who get marry later in life. Thus, the attendant increases in prevalence of complications of teenage pregnancy in this region of the world (UNICEF, 2005). In sub-Saharan Africa 70-80\% of births to teenagers occur within marriage. Teenagers who have never been married are significantly less likely to have entered motherhood (Marcen and Bellido, 2013;www.iiste.org/Journals/index.php/JEDS/article/viewFile/10699/10904). This however does not negate the fact that they are sexually active and need to be taught how to prevent unwanted pregnancies through family planning. Teenage pregnancy in a population is a means through which linkages between fertility and socio-economic variables can be examined (Sonfield, et al, 2013;

www.iiste.org/Journals/index.php/JEDS/article/viewFile/10699/10904).

It is an early warning sign of inequality in a society (Barcena, 2013; http://www.iiste.org/Journals/index.php/JEDS/article/viewFile/10699/10904). It is more common among the poor, rural dwellers compared to the wealthy and urban dwellers. Educational level is a risk factor in teenage pregnancy - the relationship is inversely proportional (Chau-Kuang, 2013;

www.iiste.org/Journals/index.php/JEDS/article/viewFile/10699/10904). Likewise, teenage pregnancy is a major cause of dropping out of school. Teenage pregnancy and motherhood has remained a major health and social concern in Nigeria because of its association with likely higher maternal morbidity and mortality as well as child morbidity and mortality (National Population Commission and ICF Macro2009; www.iiste.org/Journals/index.php/JEDS/article/viewFile/10699/1090) 
Texila International Journal of Public Health

Volume 4, Issue 4, Dec 2016

\section{Study justification}

The study has environmental, societal and economic significance. By reducing adolescent fertility rates (AFR), better utilization and distribution of resources will be achieved thus improving on people's quality of life. Government planning will also ease with controlled fertility rates. This study is also significant to public health since by lowering fertility rates, population growth and its effects will also decline. Effects like disease due to overcrowding will be curbed. Maternal, infant and child mortality will reduce. Macronutrient deficiencies and disease especially among children due to large numbers of children, lack of financial empowerment in mothers and low educational level. The study aims at filling a gap in knowledge on contraceptive uptake among adolescents and creates baseline data viable for further research. It is hoped that the findings of the study will inform policy makers on contraceptive uptake among adolescents and will contribute to the growing need for age group transformative programs in Maternal and Child Health/Family Planning

\section{Research questions}

- $\quad$ Are adolescents aware of the available contraceptives?

- Are they utilizing contraceptive services?

- What are the barriers to effective utilization of contraceptives by adolescents?

\section{Objectives}

\section{Broad objective}

The broad objective of this study is to assess the utilization of contraceptives uptake among adolescents aged 15-19 years in Nigeria.

\section{Specific objectives}

- To establish whether the contraception services are available for adolescents aged 1519 years in Nigeria.

- $\quad$ To assess awareness of contraception among adolescents aged 15-19 years in Nigeria.

- To assess contraception utilization among adolescents aged 15-19 years in Nigeria.

- $\quad$ To establish the barriers to contraceptives' utilization among adolescents aged 15-19 years in Nigeria.

\section{Literature review}

\section{Contraception}

It is the deliberate use of artificial methods or other techniques to prevent pregnancy as a consequence of sexual intercourse. Contraception is a pillar in reducing adolescent pregnancy rates.

\section{Benefits of contraception}

The reproductive choices made by young women and men have an enormous impact on their health, schooling, employment prospects and overall transition to adulthood (www.guttmacher.org/about/journals/ipsrh/2009/patterns-and-trends-adolescents-

contraceptive-use-and-discontinuation). Effective contraception uptake helps in controlling rapid population growth. Unsustainable

Population growth rates are slowed down to match the available resources. This helps achieve environmental sustainability and economic growth both regionally and nationally. (Mundo, F. D. (2012) Primary Maternal and Neonatal Health: A Global Concern. Chicago: Springer Science \& Media Centre). Other highlighted benefits of adolescent contraception are preventing pregnancy-related health risks, reducing the need for unsafe abortion, reducing infant mortality, helping to prevent HIV/AIDS, empowering youth and enhancing education and reducing adolescent pregnancies. (who.int/mediacentre/factsheets/fs351/en/) 


\section{Provision of contraception}

Although adolescent pregnancy rates in developed countries have decreased significantly over the past decade, births to adolescents remain both an individual and public health issue. As advocates for the health and well-being of all young people, recommendation that adolescents postpone consensual sexual activity until they are fully ready for the emotional, physical, and financial consequences of sex should be made. Despite this, some young people will choose not to postpone sexual activity, and thus need help to reduce risks and negative health consequences associated with adolescent sexual behaviors, including unintended pregnancies and sexually transmitted infections. (Contraception and Adolescents; Revised. 104(5):1161PediatricsNovember 2007, VOLUME 120/ISSUE 5). Providing information to adolescents about contraception does not result in increased rates of sexual activity, earlier age of first intercourse, or a greater number of partners. If adolescents perceive obstacles to obtaining contraception and condoms, they are more likely to experience negative outcomes related to sexual activity. It is important that family planning is widely available and easily accessible through midwives and other trained health workers to anyone who is sexually active, including adolescents. Midwives are trained to provide (where authorized) locally available and culturally acceptable contraceptive methods. Other trained health workers, for example community health workers, also provide counseling and some family planning methods, for example pills and condoms. For methods such as sterilization, women and men need to be referred to a clinician.(who.int/mediacentre/factsheets/fs351/en/)

\section{Contraceptive methods}

The contraceptive methods can be classified into modern and traditional methods.

\section{Modern methods}

Modern contraceptive methods were invented so couples could act on natural impulses and desires with diminished risks of pregnancy. Modern contraceptive methods are technological advances designed to overcome biology. In this regard, modern methods must enable couples to have sexual intercourse at any mutually-desired time. Contraceptive use has increased in many parts of the world, especially in Asia and Latin America, but continues to be low in subSaharan Africa. Globally, use of modern contraception has risen slightly, from 54\% in 1990 to $57.4 \%$ in 2014. (http://who.int/mediacentre/factsheets/fs351/en/) Modern methods of contraception include female and male sterilization, oral hormonal pills, the intra-uterine device (IUD), the male condom, injectable, the implant (including Norplant), vaginal barrier methods, the female condom and emergency contraception.

\section{Traditional methods}

Withdrawal (Coitus interruptus) is aimed at preventing fertilization in that, upon ejaculation during sexual intercourse, a man draws out the penis and ejaculates outside the woman's vagina and external genitalia. It offers 96\% effectiveness in preventing pregnancy when correctly and consistently used. Many couples use it because of convenience, although, its effectiveness is somehow compromised, owing to the fact that proper timing of withdrawal is difficult. (Carroll, J. (2015) Sexuality Now: Embracing Diversity. Boston: Cengage Learning) Periodic abstinence (the rhythm or calendar method) refers to avoiding unprotected vaginal sex during the woman's most fertility days. Achieved through calendar-based methods; monitoring fertile days in the cycle of menstruation, cervical mucus and body temperature monitoring. If correctly and consistently used, they form $95-97 \%$ effectiveness in preventing pregnancy, though it requires maximum cooperation among sexual partners. (Callahan, T., Caughey, A. B. (2013) Blueprints Obstetrics and Gynecology. Baltimore: Lippincott Williams \& Wilkins.) 
Texila International Journal of Public Health

Volume 4, Issue 4, Dec 2016

\section{Contraceptive utilization among adolescents}

Among sexually active youth, contraceptive use reduces the number of unplanned pregnancies. However, before using a contraceptive, youth must first have knowledge of different methods. Understanding youth sexual behaviors and contraceptive use can help improve policies addressing reproductive health knowledge and behavior among young women. Increased knowledge can empower young women to have more control over their reproductive health and access family planning resources where needs are not being met. Improvements in sexual health behavior and knowledge among youth can lead to a decrease in the spread of STIs including HIV infection as well as fewer unplanned pregnancies, which will allow for a healthier generation of families (www.prb.org/Publications/Articles/2009/westafricayouth.aspx)

More than two-third (67\%) of the adolescents in a study carried out in Ethiopia had knowledge about reproductive health. Age, living arrangement and economic status were associated with reproductive health knowledge. However, only one-fifth (21.5\%) of the adolescents had ever used reproductive health services including family planning, sexually transmitted infections treatment and information, education and communication. Reproductive health services utilization was significantly associated with age and knowledge of reproductive health. (Amanuel Alemu Abajobir and Assefa Seme; BMC Health Services Research201414:138; DOI: 10.1186/1472-6963-14-138) recommended that an intervention for improving consistent contraceptive use among adolescents be pursued.

Further buttressing this point, a study was carried out to access the student's knowledge and use of emergency contraception which is known to be safe and effective in preventing unplanned pregnancy. The study was carried out in Ilorin, Western Nigeria, using multi-stage sampling method. Data was collected using pre-tested semi-structured self-administered questionnaire. Knowledge was scored and analyzed using SPSS version 21.0 was used for data analysis. A p-value $<0.05$ was considered statistically significant.27.8\% of the respondents had good knowledge of emergency contraception. Majority of respondents (87.2\%) had never used emergency contraception. Majority of those who had ever used emergency contraception (85.7\%) used it incorrectly, using it more than 72 hours after sexual intercourse $(p=0.928)$. This shows that knowledge about Emergency contraception and prevalence of use was low. (The Pan African Medical Journal. 2016;23:74. doi:10.11604/pamj.2016.23.74.8688)

The creation of adolescent-friendly centers for reproductive health services is highly proposed if significant improvement is to be seen in contraceptive utilization among adolescents. Though a high number of adolescents know at least one contraceptive method, this knowledge does not influence them to consistently use contraceptives. Only a small percentage of the sexually active adolescents use a contraceptive method consistently. (Use of contraceptives among adolescents in Kintampo, Ghana: a cross-sectional study by Boamah EA, Asante KP, Mahama E, Manu G, Ayipah EK, Adeniji E, Owusu-Agyei S; DOIhttps://dx.doi.org/10.2147/OAJC.S56485)

\section{Barriers to contraceptive uptake among adolescents}

Race, ethnicity, age, marital status, education, income, requirements for confidential care, and fertility intentions has all been demonstrated to affect contraceptive choice (Contraception and Adolescents; Revised. 104(5):1161PediatricsNovember 2007, VOLUME 120/ISSUE 5). Parent disapproval, lack of basic information and pressure from partners were found to deter adolescents from accessing and using reproductive health services. Likewise, low parent-adolescent communication on reproductive health issues continue to be sociocultural taboos among the societies (Amanuel Alemu Abajobir and Assefa Seme;BMC Health Services Research201414:138; DOI: 10.1186/1472-6963-14-138) Adolescent-friendly centers for reproductive health services do not exist in most developing countries. This puts the adolescents off because the regular reproductive health services especially with regards to confidentiality do not encourage their visit. Regular ones are usually too judgmental and also 
stigmatizes due to lack of special training on handling of adolescents.(Use of contraceptives among adolescents in Kintampo, Ghana: a cross-sectional study by Boamah EA, Asante KP, Mahama E, Manu G, Ayipah EK, Adeniji E, Owusu-Agyei S; DOIhttps://dx.doi.org/10.2147/OAJC.S56485)

Amount of contraceptive education that providers receive appears to be insufficient and they have insufficient opportunities for continuing education on advances in contraceptive methods and changes in contraceptive protocols. Adolescents get little messages and information on the importance of contraception and the methods available. Research suggests that most adolescent girls have a strong desire to become pregnant due to internalized powerful socio-cultural values. Emotional and interpersonal barriers to the uptake of family planning services also stem from the attitudes and desires of partners and other family members regarding girls' fertility. Socio-cultural and religious norms and practices impact the use of contraception in so far as the social value they ascribe to girls versus boys and appropriate gender roles for each. Teens also face important cognitive barriers in that they lack knowledge and understanding of conception and contraception. Geographic barriers are particularly significant for rural teens and those with restricted mobility. The cost of contraception is an economic barrier for adolescents. Administrative barriers can limit the access of unmarried teens. Where teens are stigmatized for their sexuality, barriers relating to quality of care, especially the attitudes of providers are significant. (https://www.odi.org/projects/2596-barriers-contraceptive-use)

A cross-sectional study was carried out among 400 senior secondary schools students in Ojo military barracks, Lagos, Western Nigeria. Majority of them 391 (97.8\%), were in the adolescent age group (10-19 years). 67.5\% of them had correct knowledge of the use of condoms while $31.1 \%$ of the sexually active respondents have ever used any form of contraceptive with no statistically significant difference between the male and female respondents $(P=0.338)$. The most common barrier to contraceptive methods as reported by $85.1 \%$ of respondents was being too embarrassed to source for the contraceptives.(Contraceptive knowledge and practice among senior secondary schools students in military barracks in Nigeria UC Chimah, TO Lawoyin, AL Ilika, CC Nnebue)

Non-availability of wider choice of methods also reduces the ability to meet the individual needs of contraception. To examine how much contraceptive use increases as additional methods are made available to populations, data estimating contraceptive use from representative national surveys and data estimating method availability from special surveys to make comparisons for 6 modern contraceptive methods, in each of 6 years: 1982, 1989, 1994, 1999, 2004, and 2009 were used. Various method accessibility rules governing different proportions of the total population (ranging from 20\% to 80\%) that must have access to a method in order for it to qualify as "available" was used to estimate method availability. It was found that contraceptive use is greater when more methods are available to a large portion of the population, both cross-sectionally and over time. Increase in number of methods available by 1 to at least half the population gave an increase of 4-8 percentage points in total use of the 6 modern methods. A consistent pattern emerges for the relationship of contraceptive use and choice among multiple methods. Therefore, contraception use may be increased by extending the availability of current methods, by improving features of current methods, or by introducing new methods (www.ghspjournal.org/content/1/2/203.full) 


\section{Methodology}

\section{Figure}

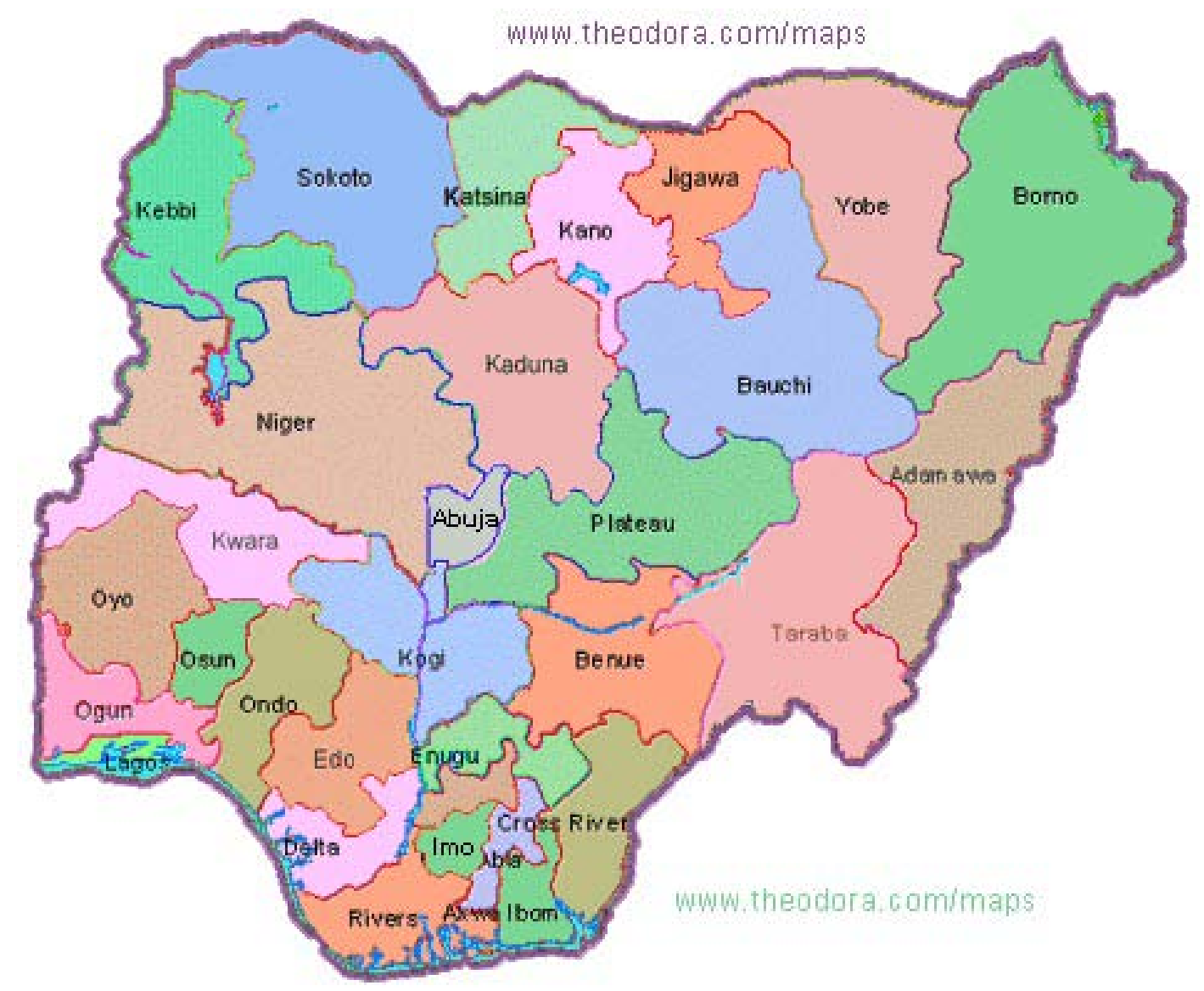

Figure 1. Nigeria lies on the west coast of Africa between latitudes $4^{\circ} 16^{\prime}$ and $13^{\circ} 53^{\prime}$ north and longitudes $2^{\circ} 40^{\prime}$ and $14^{\circ} 41^{\prime}$ east. It occupies approximately 923,768 square kilometers of land stretching from the Gulf of Guinea on the Atlantic coast in the south to the fringes of the Sahara Desert in the North. The territorial boundaries are defined by the republics of Niger and Chad in the north, the Republic of Cameroon on the east, and the Republic of Benin on the west. Nigeria is the most populous country in Africa and the 14th largest in land mass. The country's 2006 Population and Housing Census placed the country's population at $140,431,790$.

\section{Target and study population}

A nationally representative sample of 40,320 households from 904 primary sampling units (PSUs) was selected. People age 15-19 years who were usual members of the selected households or who spent the night before the survey in the selected households was eligible for individual interviews. As with previous NDHS surveys, the main objective of the 2013 NDHS was to provide reliable information on knowledge and use of family planning methods. The survey was designed to produce reliable estimates for key indicators at the national level as well as for urban and rural areas, each of the country's six geographical zones, and each of the 36 states and the Federal Capital Territory (FCT).

\section{Study design}

The cross-sectional study design will be adopted and will seek to assess the uptake of contraception among adolescents aged $15-19$ years. 


\section{Sampling}

\section{Sampling technique}

The sample for the 2013 NDHS was a stratified sample, selected independently in three stages from the sampling frame. Stratification was achieved by separating each state into urban and rural areas. In the first stage, 893 localities were selected with probability proportional to size and with independent selection in each sampling stratum. In the second stage, one EA was randomly selected from most of the selected localities with an equal probability selection. In a few larger localities, more than one EA was selected. In total, 904 EAs were selected. After the selection of the EAs and before the main survey, a household listing operation was carried out in all of the selected EAs. The household listing consisted of visiting each of the 904 selected EAs, drawing a location map and a detailed sketch map, and recording on the household listing forms all occupied residential households found in the EA with the address and the name of the head of the household. If a selected EA included less than 80 households, a neighboring EA from the selected locality was added to the cluster and listed completely. The resulting list of households served as the sampling frame for the selection of households in the third stage. In the third stage of selection, a fixed number of 45 households were selected in every urban and rural cluster through equal probability systematic sampling based on the newly updated household listing

\section{Sample size determination}

A nationally representative sample of 40,320 households from 904 primary sampling units (PSUs) was selected. 38,904 were found to be occupied at the time of the fieldwork. Of the occupied households, 38,522 were successfully interviewed, yielding a household response rate of 99 percent. All adolescents age 15-19 years who were usual members of the selected households or who spent the night before the survey in the selected households was eligible for individual interviews.

\section{Sampling procedure}

Nigeria is divided into states. In turn, each state is subdivided into local government areas (LGAs) and each LGA into smaller (secondary and tertiary) localities. Nigeria has 36 states and a Federal Capital Territory (FCT). These states are subdivided into 774 LGAs. Furthermore, the states are regrouped by geographical location to form six zones. In addition to these administrative units and geographical zones, each locality was subdivided into convenient areas called census enumeration areas (EAs). The average number of households per EA in the corresponding locality frame was assigned to each EA. The EAs in Nigeria are small in size, with an average of 211 inhabitants (equivalent to 48 households). Since these EAs were too small to be DHS clusters, the 2013 NDHS included several EAs per DHS cluster (with a preferred minimum cluster size of 80 households).

\section{Inclusion criteria}

Inclusive criteria are all the adolescents who are within the sexually active age (15 - 19 years) and who will give consent and willing to participate in the study. Adolescents below 15-19 years though sexually active will be excluded from the study.

\section{Data and data collection tools}

Both qualitative and quantitative data will be collected during the study using structured questionnaires and interview guides. The questionnaires will consist of three parts. Three questionnaires were used in the 2013 NDHS: the Household Questionnaire, the Woman's Questionnaire, and the Man's Questionnaire. The content of these questionnaires was based on model questionnaires developed by the MEASURE DHS programs. The model questionnaires were modified according to the country's requirements, in consultation with a broad spectrum of government ministries and agencies, nongovernmental organizations, and international donors, to reflect relevant issues such as family planning, The first part will 
Texila International Journal of Public Health

Volume 4, Issue 4, Dec 2016

contain demographic questions, the second part will contain the known and preferred adolescent contraceptive methods and the last will consist of questions relating to barriers to contraceptive uptake. Prior to the start of data collection, the purpose of conducting the study will be explained to the participants for them to express their willingness by granting consent.

\section{Data collection procedures}

The Household, female's, and male's Questionnaires were pretested in four locations in Makurdi (northern Nigeria), where the residents are predominantly Hausa, Yoruba, English, and Igbo speaking. The teams were divided according to languages. The supervisors and editors were drawn from among the trainees. The questionnaires were pretested in 120 households. A debriefing session was held at the end of the pretest fieldwork. Based on observations from the field and suggestions made by the pretest teams, revisions were made in the wording and translations of the questionnaires. Logistical arrangements for the survey were also discussed.

\section{Data processing and analysis}

After data collection is completed, data entry, cleaning and analysis will be done by using the Statistical Package for Social Sciences (SPSS) software, version 20 Program. In order to describe the descriptive statistic, frequencies and percentages will be computed and represented in bar graphs, pie charts and tables. Qualitative data will be analyzed in relation to the study variables. Chi-square test will be used to measure the strength of associations between the various variables where a p-value of $=$ or $<0.05$ will be considered statistically significant.

\section{Expected outcome}

The number of adolescents between the ages 15-19 years on contraceptive will be established. Levels of awareness, utilization and barriers to contraceptives' utilization among them will also be established.

\section{Results and discussion}

Table 1.0. Exposure to family planning messages among adolescents $15-19$ years

\begin{tabular}{|l|l|l|}
\hline & FEMALE (7820) & MALE (3619) \\
\hline RADIO & 24.0 & 28.9 \\
\hline TV & 12.6 & 14.6 \\
\hline NEWSPAPER/MAGAZINE & 4.0 & 4.4 \\
\hline POSTER/LEAFLET/BROCHURE & 9.0 & 10.8 \\
\hline OTHER & 3.4 & 3.3 \\
\hline NO MEDIA SOURCE & 71.2 & 65.2 \\
\hline
\end{tabular}

Table 2.0. Knowledge and use of contraceptive methods among adolescents aged 15-19 years

\begin{tabular}{|l|l|l|}
\hline & FEMALE (2251) & MALE (41) \\
\hline $\begin{array}{l}\text { HEARD OF ANY } \\
\text { METHOD }\end{array}$ & 67.0 & 86.7 \\
\hline $\begin{array}{l}\text { HEARD OF ANY } \\
\text { MODERN METHOD }\end{array}$ & 64.4 & 85.7 \\
\hline
\end{tabular}




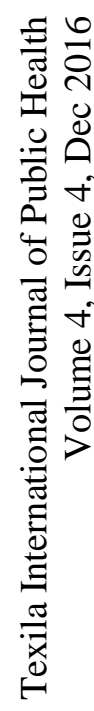

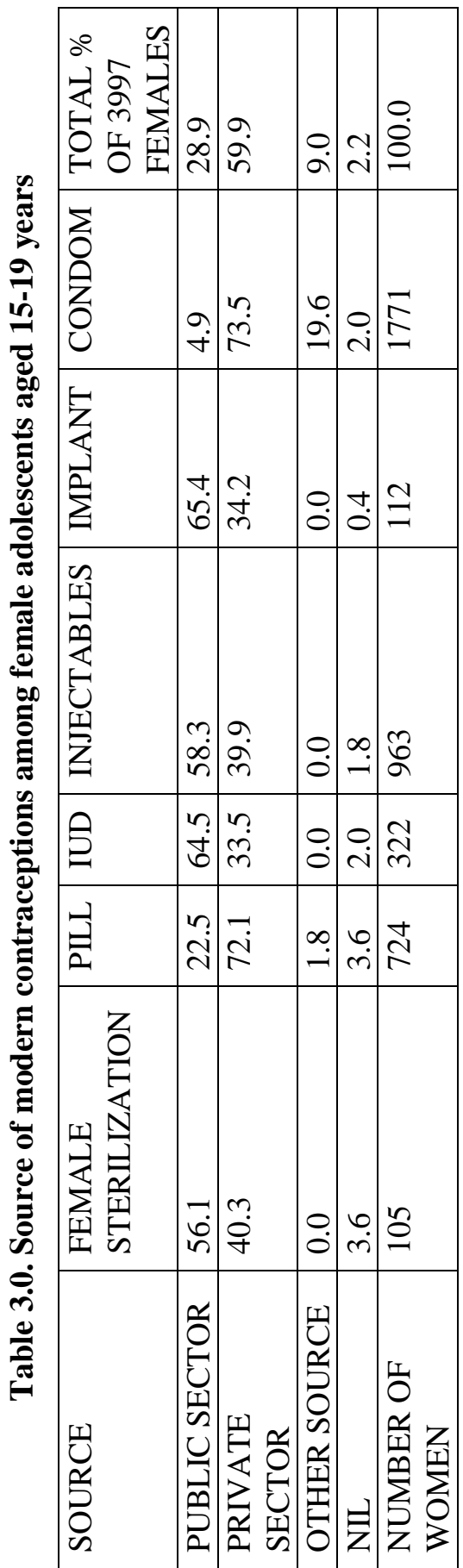


Texila International Journal of Public Health

Volume 4, Issue 4, Dec 2016

\section{Charts representing table 3.0}
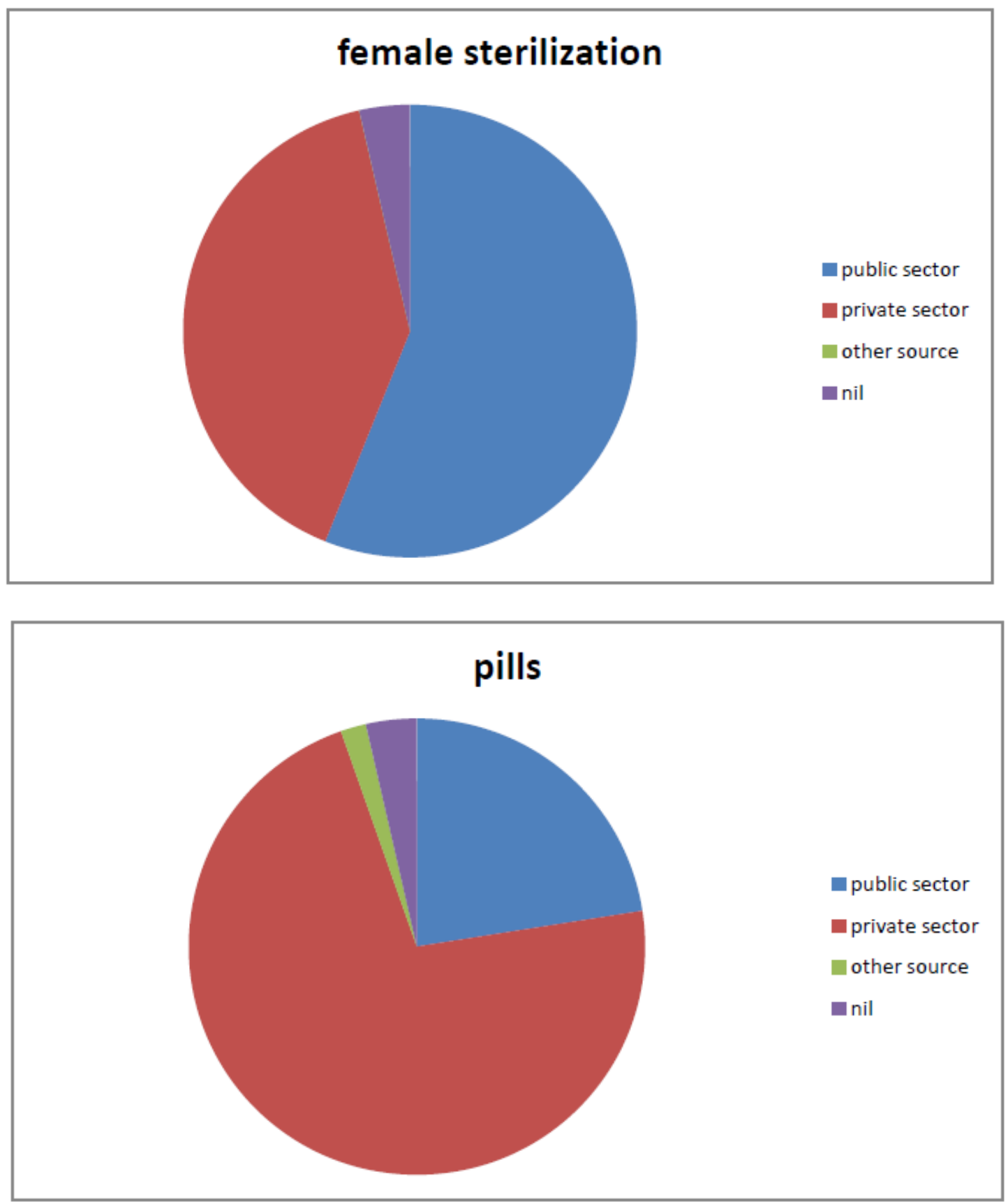


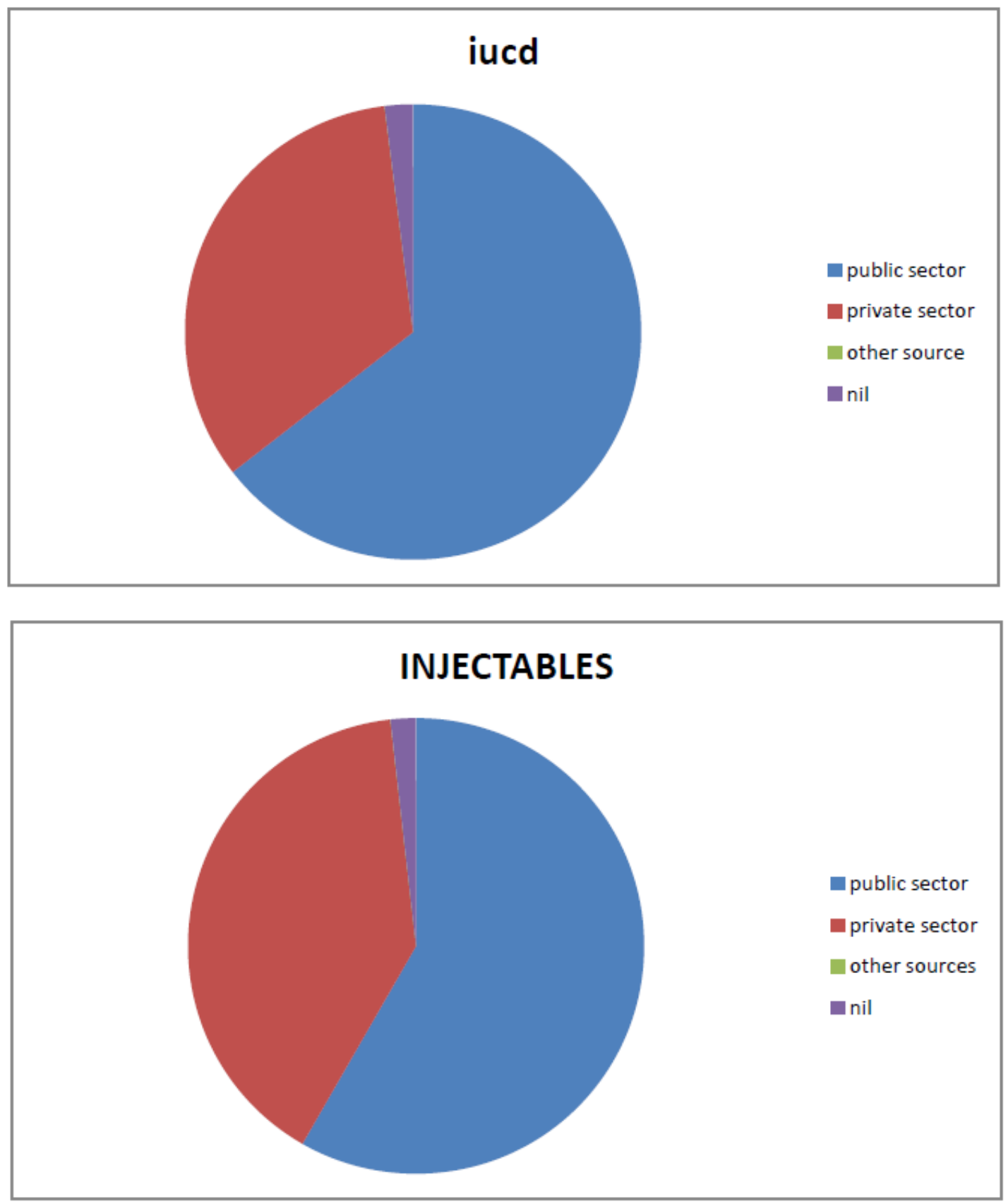


Texila International Journal of Public Health

Volume 4, Issue 4, Dec 2016
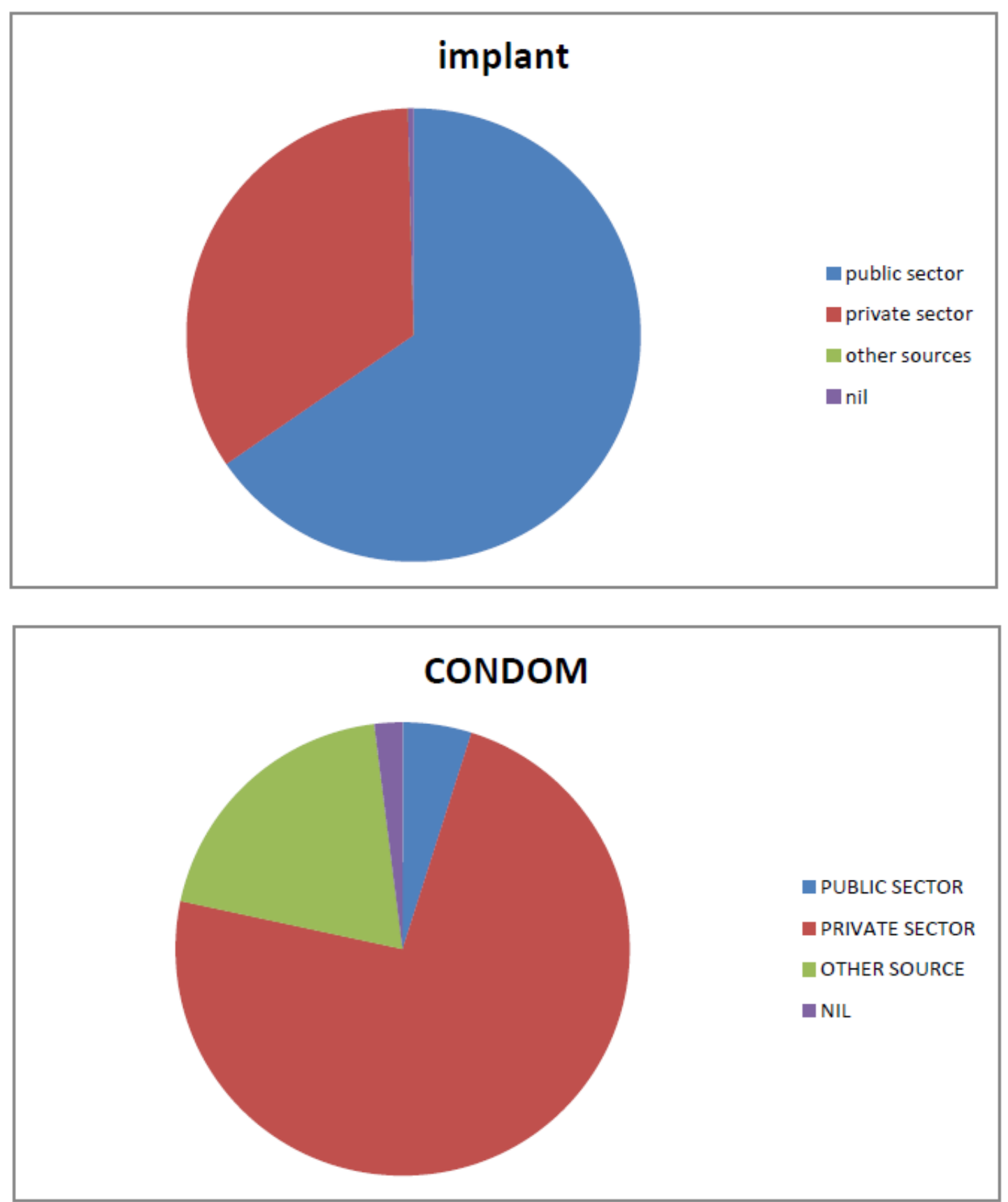

Table 4.0. Need and demand for family planning in females aged 15-19 years

\begin{tabular}{|l|l|l|l|}
\hline & FOR SPACING & FOR LIMITING & TOTAL \\
\hline MET NEED & 6.1 & 0.1 & 6.2 \\
\hline UNMET NEED & 6.2 & 0.0 & 6.2 \\
\hline TOTAL DEMAND & 12.3 & 0.1 & 12.4 \\
\hline
\end{tabular}


Texila International Journal of Public Health

Volume 4, Issue 4, Dec 2016

Table 5.0. Contact of Non-Users with Family Planning Responders Out Of 7340 Adolescents

\begin{tabular}{|l|l|l|l|}
\hline FIELD WORKER VISITED & VISITED HEALTH & & \multirow{2}{*}{ NEITHER } \\
AND DISCUSSED FP & $\begin{array}{l}\text { FACILITY IN PAST } \\
12 \text { MONTHS }\end{array}$ & & \\
& DISCUSSED FP & $\begin{array}{l}\text { DID NOT } \\
\text { DISCUSS } \\
\text { FP }\end{array}$ & \\
\cline { 2 - 4 } & $1.6 \%$ & $8.2 \%$ & $96.9 \%$ \\
\hline
\end{tabular}

Table 6.0 shows descriptive statistics for selected indicator variables in the logistic regression models Nigeria Demographic and Health survey for females only.

Table 7.0 shows effects of selected explanatory variables on the odds of an adolescent being currently pregnant (Model 1); having borne a child in the five years preceding the survey (model 2) and either of the two models (model 3).

Table 6.0

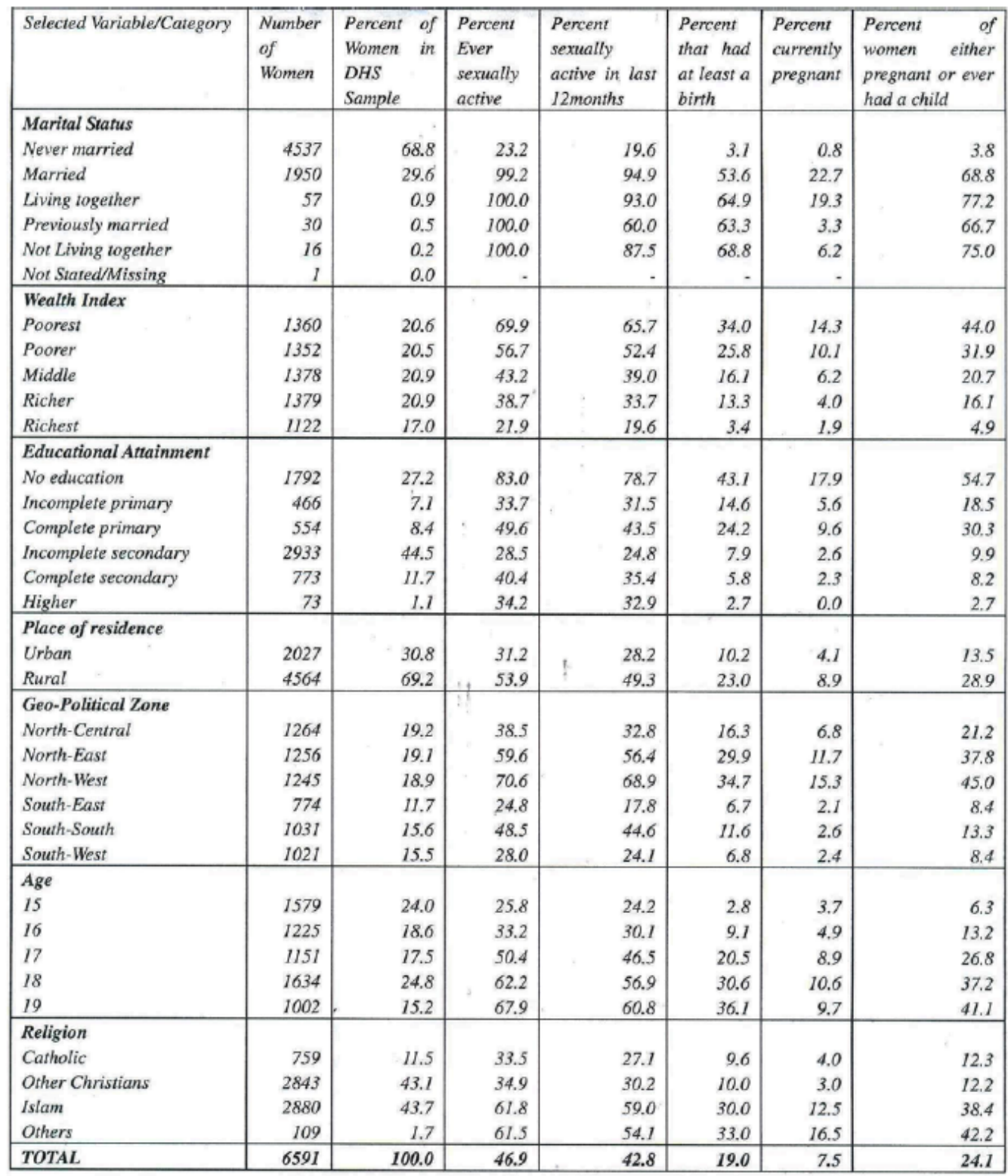


Texila International Journal of Public Health

Volume 4, Issue 4, Dec 2016

\section{Discussion}

The above tables and charts are in support of presence of met needs of contraception among adolescents. It shows there is a huge lack of knowledge of contraception, the private sector plays and still has a great role to play in bridging the gap of unmet needs of contraception and this role cannot be undermined. Most adolescents interviewed needed contraception for spacing number of children than for limiting - most adolescent pregnancies take place within the context of marriage in developing countries and is worse among people of low socioeconomic class. $30 \%$ of every adolescent is currently married in Nigeria, $19.6 \%$ of those who have never been married have been sexually active. Two thirds of those cohabiting, previously married and those not living together are currently pregnant or had borne a child. Those who are not married or previously married are less, significantly so, to be currently pregnant relative to those in marital unions. These show that adolescent marriage is still a threat to the future of our generation. Thus, investing into meeting the contraceptive needs of the adolescent population is a move in the right direction. International data over 27 years show that as each additional contraceptive method became available to most of the population, overall modern contraceptive use rose. But in 2009 only 3.5 methods, on average, were available to at least half the population in surveyed countries.

\section{Conclusion and recommendations}

Adolescents have unmet family planning needs. Enough has not been done to reduce this burden especially in rural areas and among those of low socio-economic status. Based on the complications arising from failure to meet the adolescent needs of contraceptives, it is recommended that efforts should be intensified to promote safe sexual practice and contraceptive use in this age group. Five key empowerment dimensions that need to be tackled if adolescents' contraceptive needs are to be given the strategic, multi-pronged policy attention that they merit are: socio cultural, educational, interpersonal relationships, girl child rights and empowerment with practical knowledge. Emphasis is on girls here because they bear the most brunt of problems of unsafe sex.

1. Family planning programs should strive to provide widespread access to a range of methods.

2. It is not the government's duty alone to meet the contraceptive need of the populace; there must be partnership with other stake holders.

3. Policies in support of adolescent contraception need must be encouraged and passed into law.

4. Different channels

5. Adolescent friendly centres should be open in all areas and made accessible to all so adolescents can feel free to walk into anyone at anytime and receive proper counselling.

6. Training and retraining of all family planning workers.

7. Confidentialty of the adolescents who seek to have family planning must not be breached.

8. Parents need to be educated that this transitional stage in the life of a child is very important. Thus, they must give their full support to their wards so they can turn out successful. They are the first contacts of these adolescents and they need to pass the message of sex education across well without being judgmental.

9. Education is key to making informed choices, every child must be educated.

10. Socioeconomic discrepancies should become negligible if meaningful strides are to be recorded nationwide.

\section{Acknowledgement}

I want to acknowledge the Almighty God without whom I am nothing. He gave the grace, ability and also made provision for me to be a part of this class of Master of Public health. I thank my husband for his unflinching support through the program and up till now. To my wonderful children, I say thank you for allowing me get a 
second degree. To my mother, I say you are the best. Thanks for always giving up your comfort for we, your children. To all my siblings and friends, you are appreciated. To all my teachers, thank you. To all my student coordinators, thank you for making life easy for me.

\section{References}

[1]. Australas Med J. 2011; 4(1): 43-48. Published online 2011 Jan 31. doi: 10.4066/AMJ.2011.499

[2]. Attitude of Parents and Adolescents Towards Contraceptive Use by Adolescents in Alajo, Ayawaso Central Submetro of Accra Maya, E.T. --hdl.handle.net/123456789/5150www.prb.org/Publications/Articles/2013/adolescent-fertility.aspx

www.who.int/maternal_child_adolescent/topics/maternal/adolescent_pregnancy/en/

[3]. Social Dynamics of Adolescent Fertility in Sub-Saharan Africa (1993)www.nap.edu/catalog/2220/social-dynamics-of-adolescent-fertility-in-sub-saharan-africa

[4]. Panday, et al., 2009, UNICEF, 2005

[5]. Marcen and Bellido, 2013;www.iiste.org/Journals/index.php/JEDS/article/viewFile/10699/10904

[6]. Sonfield, et al, 2013; www.iiste.org/Journals/index.php/JEDS/article/viewFile/10699/10904

[7]. Barcena, 2013; www.iiste.org/Journals/index.php/JEDS/article/viewFile/10699/10904

[8]. Chau-Kuang, 2013; www.iiste.org/Journals/index.php/JEDS/article/viewFile/10699/10904

[9]. National Population Commission and ICF

Macro2009;www.iiste.org/Journals/index.php/JEDS/article/viewFile/10699/1090

[10]. www.guttmacher.org/about/journals/ipsrh/2009/patterns-and-trends-adolescents-contraceptiveuse-and-discontinuation

[11]. Mundo, F. D. (2012) Primary Maternal and Neonatal Health: A Global Concern. Chicago: Springer Science \& Media Centre

[12]. who.int/mediacentre/factsheets/fs351/en/

[13]. Contraception and Adolescents; Revised. 104(5):1161PediatricsNovember 2007, VOLUME 120/ISSUE 5

[14]. Carroll, J. (2015) Sexuality Now: Embracing Diversity. Boston: Cengage Learning

[15]. Callahan, T., Caughey, A. B. (2013) Blueprints Obstetrics and Gynecology. Baltimore: Lippincott Williams \& Wilkins.

[16]. www.prb.org/Publications/Articles/2009/westafricayouth.aspx

[17]. Amanuel Alemu Abajobir and Assefa Seme; BMC Health Services Research201414:138; DOI: 10.1186/1472-6963-14-138

[18]. The Pan African Medical Journal. 2016;23:74. doi:10.11604/pamj.2016.23.74.8688

[19]. Use of contraceptives among adolescents in Kintampo, Ghana: a cross-sectional study by Boamah EA, Asante KP, Mahama E, Manu G, Ayipah EK, Adeniji E, Owusu-Agyei S; DOI https://dx.doi.org/10.2147/OAJC.S56485

[20]. Contraception and Adolescents; Revised. 104(5):1161PediatricsNovember 2007, VOLUME 120/ISSUE 5

[21]. Amanuel Alemu Abajobir and Assefa Seme; BMC Health Services Research201414:138; DOI: 10.1186/1472-6963-14-138

[22]. Use of contraceptives among adolescents in Kintampo, Ghana: a cross-sectional study by Boamah EA, Asante KP, Mahama E, Manu G, Ayipah EK, Adeniji E, Owusu-Agyei S; DOI https://dx.doi.org/10.2147/OAJC.S56485

[23]. www.odi.org/projects/2596-barriers-contraceptive-use

[24]. Contraceptive knowledge and practice among senior secondary schools students in military barracks in Nigeria UC Chimah, TO Lawoyin, AL Ilika, CC Nnebue

[25]. www.ghspjournal.org/content/1/2/203.full 